\title{
CONNG THONG TIN ĐIENTỬ
}

\section{HỌC VIỆN CẢNH SÁT NHÂN DÂN}

\section{A}

NGHIÊN CỨ - TRAO ĐỔ

Nhìn ra thế giới|Giáo dục - Đào tạo|Đại học 4.0

Thứ Ba, 24/9/2019 9:29'(GMT+7)

A

\section{Về vai trò của nghiên cứu trong giáo dục Việt Nam thời đại 4.0}

Cách mạng 4.0 đã và đang mang đến sự thay đổi lớn trong đời sống của người dân Việt Nam. Sự tiện dụng của Grab, khả năng cập nhật 24/24 của Facebook, hay sự đa dạng về nội dung của YouTube thúc đẩy xã hội tiến tới thời đại mới của khởi nghiệp điện toán (Vuong, 2019). Ở đó, mỗi cá nhân đều có cơ hội để khởi nghiệp thông qua sự kết nối đến khắp mọi nơi trên thế giới của Internet và sức mạnh tính toán nằm gọn trong long bàn tay. Hiện nay, sản xuất video trên YouTube, cho thuê nhà qua AirBnb, hay chạy xe cho Grab tạo ra công việc có khả năng tạo lợi nhuận cho người tham gia thị trường, dù là người lao động, hay tổ chức cung ứng dịch vụ.

Trong bối cảnh đó, giáo dục trở nên quan trọng hơn bao giờ hết trong chuẩn bị cho thế hệ tương lai các tri thức cần thiết. Tuy nhiên, sau một số vụ việc nghiêm trọng xảy ra thời gian gần đây thì giáo dục Việt Nam đang cần hơn những thay đổi quan trọng trong cơ cấu và nhiệm vụ.

\section{Hiện trạng giáo dục Việt Nam}

Các trường đại học tại Việt Nam hiện nay đều có chức năng, định hướng chính là giảng dạy. Theo Pham và Hayden (2019), chức năng nghiên cứu chủ yếu được giao phó cho một số viện nghiên cứu chuyên môn riêng biệt. Tuy nhiên, trong thời gian gần đây, sự thay đổi cũng diễn ra rõ rệt khi hơn 20000 giảng viên đại học đang được hỗ trợ để làm nghiên cứu sinh tiến sĩ. Mặc dù vậy, một số nghiên cứu gần đây chỉ ra rằng hệ thống đào tạo hiện nay vẫn còn tồn đọng các vấn đề như sinh viên có nhiều thiếu sót về kĩ năng khi tốt nghiệp (Tran, 2018), hay bản thân các trường cũng cần thêm các chương trình phát 
triển kĩ năng (Tran, 2017a, 2017b). Trong khi đó, đào tạo du lịch và khách sạn tại Việt Nam được Le, McDonald và Klieve (2018) chỉ ra sự chênh lệch rõ rệt giữa chương trình đào tạo và thực tiễn, sinh viên ra trường thường kém kĩ năng hơn so với các học viên học nghề. Một số nghiên cứu khác thì chỉ ra vấn đề với các chương trình giảng dạy bằng tiếng Anh và các chương trình tiên tiến được quan tâm rộng rãi nhưng chất lượng lại đem lại cũng chưa quá khác biệt, đồng thời kéo theo hệ quả là sự lơ là với các chương trình bằng tiếng Việt (Tran and Nguyen, 2018; Tran, Hoang \& Vo, 2019).

Khi các vấn đề về chương trình giảng dạy còn tồn đọng, cùng với một khía cạnh quan trọng trong giáo dục là nghiên cứu chưa được phát triển đúng mức, thì các trường đại học Việt Nam cũng chưa để lại được dấu ấn rõ rệt trên trường quốc tế. Nếu chỉ xét riêng trong phạm vi châu Á, theo QS Ranking, chỉ có hai trường Đại học Quốc gia tại Hà Nội (124) và thành phố Hồ Chí Minh (144) có thứ hạng tương đối, ở nửa sau của top 500 chỉ có thêm bốn trường Đại học Bách khoa Hà Nội $(261$ - 270), Đại học Tôn Đức Thắng (291 - 300), Đại học Cần Thơ (351 - 400) và Đại học Huế (451 - 500). Tại hai bảng xếp hạng toàn cầu thì Việt Nam thậm chí còn không xuất hiện (trong bảng Times Higher Education - THE) hoặc chỉ có thứ hạng rất khiêm tốn (nửa dưới cùng trong top 1000 của QS Ranking. Kết quả này hoàn toàn không bất ngờ bởi các tiêu chí được sử dụng trong bảng xếp hạng bao gồm cơ sở vật chất, năng lực đội ngũ nhân sự và chất lượng nghiên cứu đều không phải là thế mạnh của các trường đại học Việt Nam (Hayden \& Thiep, 2010). Hiện nay, trong điều kiện kinh tế phát triển thì cơ sở vật chất của các trường đại học đang được cải thiện tốt hơn, nhưng chất lượng nhân sự và năng lực nghiên cứu thì vẫn đang trong giai đoạn hội nhập và phát triển.

Thực trạng nghiên cứu khoa học tại Việt Nam

Trong khi đó, đầu tư khoa học tại Việt Nam hiện chưa tạo được niềm tin vì còn thiếu quy chuẩn sản phẩm đầu ra. Nếu xét trên tiêu chí về công bố quốc tế, đặc biệt là trong KHXHNV, số các trường đại học có nghiên cứu vẫn còn rất ít ỏi và chỉ dựa trên đóng góp của một số ít các nhà nghiên cứu. Nếu nhìn vào Bảng 1 dưới đây có thể thấy ngay cả những đại học dẫn đầu về năng suất nghiên cứu trong lĩnh vực KHXHNV cũng vẫn cho thấy số lượng công bố quốc tế chưa tương xứng với tiềm năng.

Bảng 1. Các cơ quan Việt Nam có năng suất nghiên cứu KHXHNV cao (Tính đến ngày 05-05-2019 theo CSDL SSHPA) 


\begin{tabular}{|l|l|}
\hline Cơ quan & Công bố quốc tế \\
\hline Đại học Quốc gia Hà Nội & 271 \\
\hline Đại học Kinh tế Quốc dân & 165 \\
\hline Đại học Y Hà Nội (Chỉ tính ngành Y Xã hội) & 148 \\
\hline Đại học Kinh tế thành phố Hồ Chí Mình & 112 \\
\hline Đại học Quốc gia thành phố Hồ Chí Mình & 108 \\
\hline Viện Hàn lâm Khoa học Xã hội & 105 \\
\hline Bộ Y tế & 72 \\
\hline Đại học Duy Tân & 70 \\
\hline
\end{tabular}

Trong thực tế, các nghiên cứu trắc lượng khoa học cho thấy những năm gần đây, sản lượng nghiên cứu của Việt Nam có tỉ lệ tăng trưởng khá tốt, khoảng 17 - $20 \%$ một năm (Manh, 2015; Nguyen, Ho-Le, \& Le, 2017). Tuy nhiên, tốc độ tăng trưởng này vẫn chưa thể đưa Việt Nam lên ngang hàng với các quốc gia top đầu về nghiên cứu trong khu vực ASEAN như Singapore, Thái Lan hay Malaysia (Tuan \& Ly, 2011). Chưa kể, những con số nêu trên bao hàm tất cả các nghiên cứu khoa học của Việt Nam, tính cả khối ngành khoa học tự nhiên vốn hội nhập sớm hơn và công bố quốc tế từ lâu đã trở thành tiêu chuẩn phổ biến.

Chỉ riêng lĩnh vực KHXHNV, các thống kê về năng suất và sản lượng còn ở mức hạn chế hơn. Khi nghiên cứu về năng suất lao động của các nhà nghiên cứu KHXHNV tại Việt Nam dựa trên cơ sở dữ liệu SSHPA, với cấu trúc và quy cách kỹ thuật trình bày trong Vuong et al. (2018), tính đến ngày 5 tháng 5 năm 2019, chỉ có 2443 công bố quốc tế bởi 1445 tác giả tác giả Việt Nam được ghi nhận. Điều này có nghĩa mức năng suất khoa học trung bình 1 tác giả Việt trong KHXH\&NV qua giai đoạn 11 năm đang ở mức rất thấp nếu so sánh với tổng thể nghiên cứu trong nước, cụ thể với các ngành KHTN và kỹ thuật công nghệ.

Tổng sản lượng của ngành KHXH\&NV hàng năm trong giai đoạn 2008 - 2019 (ngày 05-05) được thể hiện rõ hơn trong Hình 1. Mặc dù tốc độ tăng trưởng khá đều đặn nhưng cũng phải mất đến 5 năm để sản lượng công bố hàng năm có sự thay đổi rõ rệt. Chỉ từ năm 2014 đến 2018, tổng sản lượng đã gần gấp đôi so với 6 năm trước đó.

$400-$ 


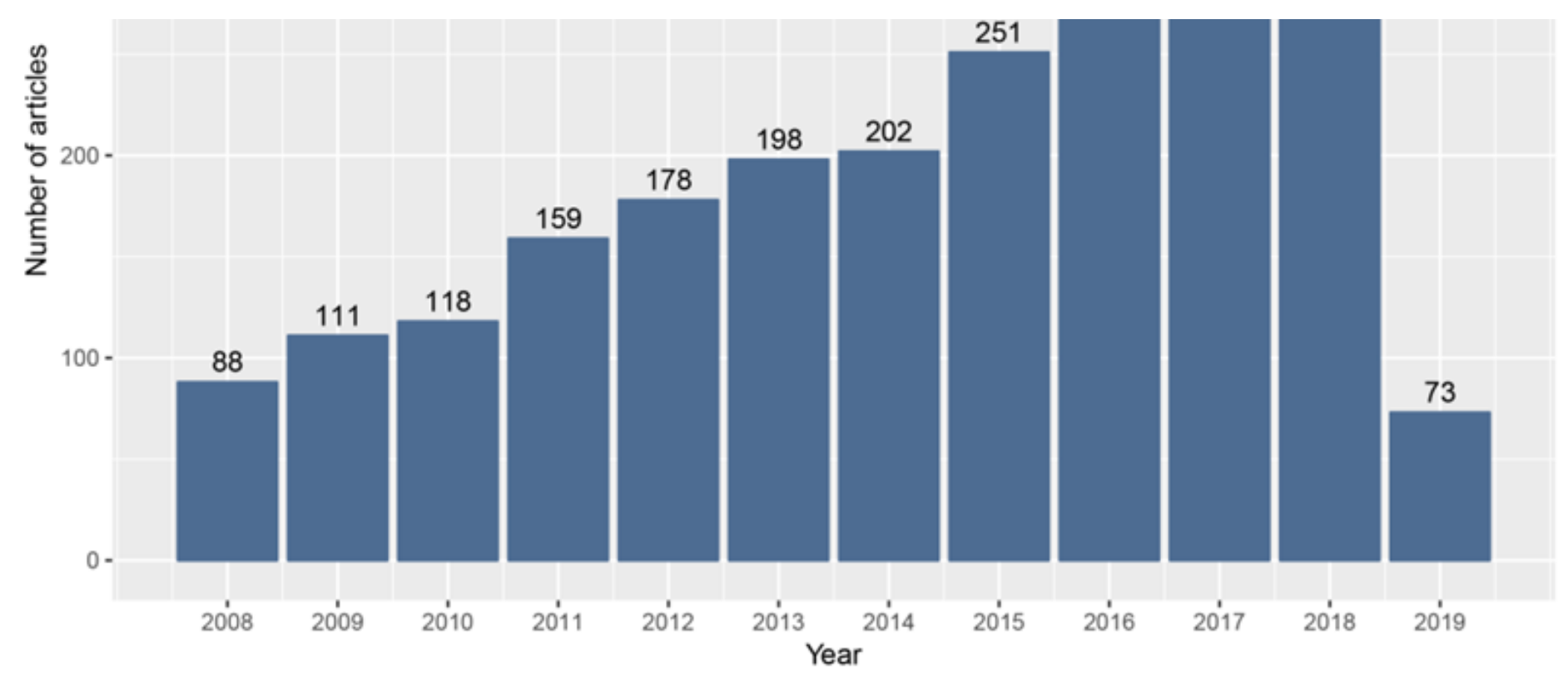

Hình 1. Tổng sản lượng nghiên cứu KHXHNV Việt Nam trong giai đoạn 2008 - 2019 tính đến ngày 05-05-2019 theo CSDL SSHPA)

Trước ngưỡng cửa hội nhập quốc tế với nền kinh tế tri thức và chia sẻ, việc các trường đại học Việt Nam đi đầu trong cải cách nền giáo dục, thông qua cải thiện năng lực nghiên cứu và công bố quốc tế, là điều không thể tránh khỏi. Hiện nay, hàng loạt các trường đại học như trường Đại học Nguyễn Tất Thành, trường Đại học Duy Tân, trường Đại học Tôn Đức Thắng, hay trường Đại học Phenikaa đang tăng tốc trên mặt trận nghiên cứu, bao gồm cả việc gắn liền kết quả nghiên cứu với lợi ích tài chính cho các công bố quốc tế lên tới hàng trăm triệu đồng (Hung, 2019) cho thấy sự thay đổi đáng kể.

Trong Hình 2, quá trình hợp tác quốc tế trong nghiên cứu khoa học thông qua đồng tác giả nghiên cứu đã có sự thay đổi lớn trong 10 năm, 2008 đến 2018. 
(a)

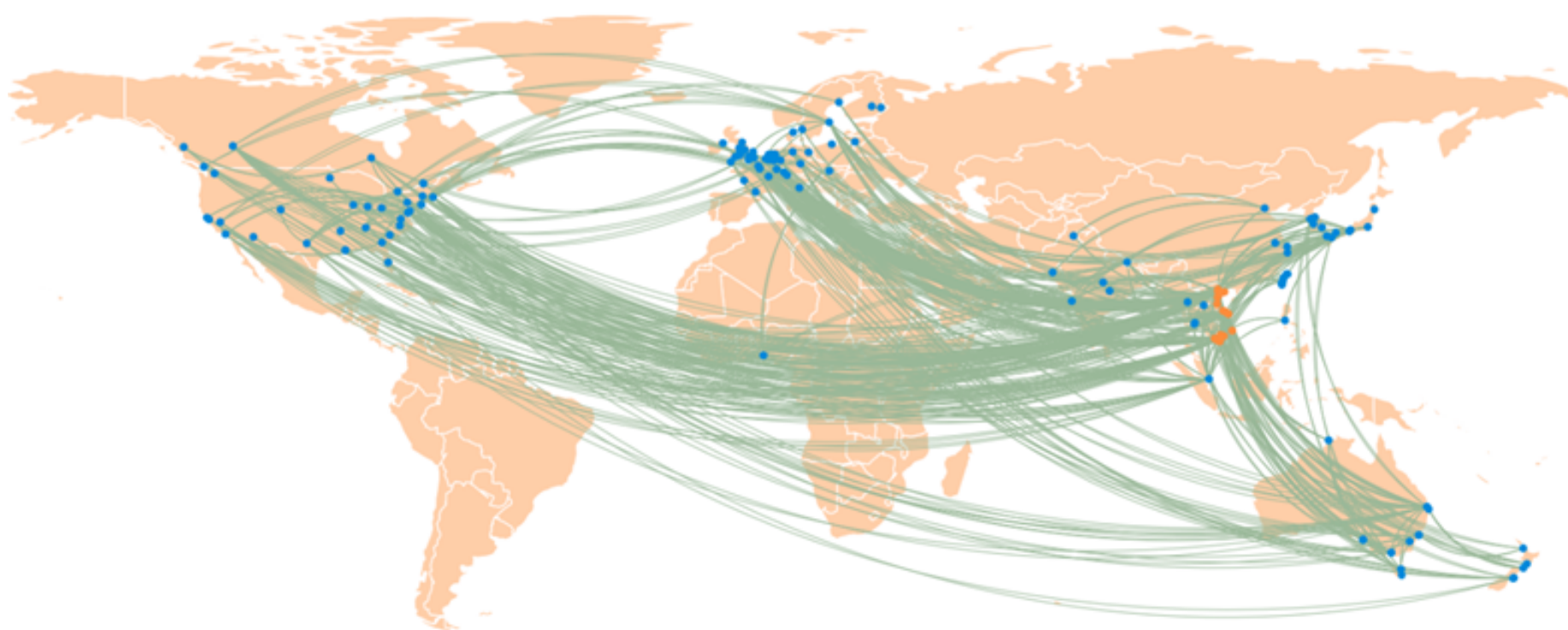

(b)

Hình 2. Hợp tác quốc tế trong nghiên cứu KHXHNV Việt Nam trong năm 2008 (a) và 2018 (b).

Xét trong bối cảnh hội nhập và phát triển, việc tăng cường hợp tác quốc tế là một hướng đi cụ thể để các nhà nghiên cứu Việt Nam có thể học hỏi các quy chuẩn quốc tế. Tuy nhiên, các trường đại học trong nước cũng không vì thế mà bỏ qua phát triển sức mạnh nội tại, đảm bảo và đẩy mạnh các yêu cầu chất lượng và hiệu quả đầu tư khoa học, dựa trên tiêu chuẩn quốc tế (Vuong, 2018).

\section{Giá trị của nghiên cứu khoa học}

Định nghĩa nghiên cứu khoa học tại Việt Nam hiện nay vẫn còn nhiều điểm mờ và dễ gây hiểu nhầm. Ví dụ, từ 'nghiên cứu' cũng được dùng trong kinh doanh như 'nghiên cứu thị trường'. Tuy nhiên, sắc thái nghĩa của nó khác hẳn so với nghiên cứu học thuật hay nghiên cứu khoa học.

Nghiên cứu khoa học, với mục tiêu cụ thể nhất là tạo ra lượng thông tin khoa học mới với chất lượng có thể vượt qua phản biện để công bố quốc tế, hướng đến tri thức, đặt ra vấn đề, và thậm chí đi đến giải quyết vấn đề. Hiện nay, vấn đề phát triển kinh tế, khoa học ứng dụng, cải thiện đời sống của người dân đang là những câu hỏi được quan tâm.

Trong giáo dục, bên cạnh công việc giảng dạy, nghiên cứu khoa học và công bố quốc tế 
là những đóng góp thiết thực khác của mỗi nhà giáo tới xã hội. Công việc này trước tiên tạo ra các tri thức gốc, đóng góp thêm vào sự hiểu biết của mỗi người Việt Nam về Việt Nam. Tiếp đó, việc tạo ra tri thức gốc cũng đồng thời cải thiện năng lực chuyên môn của mỗi nhà giáo, đóng góp vào sự phát triển, đào tạo thế hệ tương lai. Cuối cùng, nghiên cứu khoa học đóng góp trực tiếp vào việc xây dựng thương hiệu và niềm tin với giáo dục Việt Nam.

Hoạt động giáo dục tại Việt Nam hiện nay dành nhiều sự quan tâm đến giảng dạy và đào tạo. Tuy nhiên, các giáo trình chính thức, sẵn có thường sẽ cập nhật muộn hơn so với tình hình thực tế. Hơn nữa, trong thời đại Internet ngày nay, tốc độ thông tin được tính theo giờ, thậm chí từng phút, vì thế yêu cầu học sinh bám theo chương trình sách giáo khoa một cách cứng nhắc là tự hạn chế khả năng tiếp cận tri thức mới. Hoạt động nghiên cứu vì thế tạo ra một hệ sinh thái hợp lí hỗ trợ cho công việc giảng dạy. Thông qua nghiên cứu, các giáo viên được liên tục cập nhật với các kết quả nghiên cứu mới, các phương pháp mới được sản suất hàng ngày. Các tri thức mới đó sẽ giúp các giáo viên cải biến chương trình phù hợp để sinh viên có khả năng tiếp cận liên tục với các nguồn tri thức quan trọng.

Bên cạnh đó, giáo dục sau đại học, hay hướng dẫn nghiên cứu sinh tiến sĩ cũng đòi hỏi người đứng lớp phải có sự am hiểu nhất định với các hoạt động khoa học. Các yêu cầu đó được chứng minh thực tế thông qua sản phẩm: công bố quốc tế.

Việc cải thiện thứ hạng của các trường đại học trên các bảng xếp hạng toàn cầu đóng vai trò quan trọng trong việc tạo danh tiếng, mang lại các giải thưởng quốc tế danh giá, qua đó thu hút nguồn đầu tư cho nhà trường. Nếu xét riêng trong bối cảnh các trường đại học Mỹ, 115 trường thuộc top đầu tiên cũng đồng thời có năng suất nghiên cứu cao nhất (Labaree, 2018). Chất lượng nghiên cứu là một yếu tố đáng tin cậy với các tiêu chuẩn khắt khe về bình duyệt, biên tập và hệ thống chỉ mục hóa các tạp chí của ISI Web of Science hay Scopus. Uy tín của các trường đại học dựa trên sản phẩm khoa học là điều kiện tiên quyết trong việc hình thành mối quan hệ lâu dài với các quỹ đầu tư khoa học.

Việc công bố quốc tế cũng cho thấy nhà nghiên cứu đang thúc đẩy giới hạn của cả bản thân lẫn tri thức. Quá trình để có được một công bố quốc tế là không hề dễ dàng với thời gian chuẩn bị bản thảo, chờ đợi, và trả lời phản biện có thể kéo dài đến cả năm. Vì vậy, mỗi bản thảo luôn đòi hỏi tư duy chỉnh chu, sử dụng các phương pháp mới để nói về các câu chuyện mới. Mặc dù mang lại cảm giác gò bó nhưng quá trình lao động, làm việc 
luôn đòi hỏi sự sáng tạo cao. Thông qua thúc đẩy giới hạn của bản thân, mỗi nhà nghiên cứu cũng đồng thời đóng góp cho tri thức tới nhân loại. Đó có thể là sự hiểu biết về con người, văn hóa, hay kinh tế Việt Nam, hoặc cũng có thể là những đóng góp lớn lao hơn về tư tưởng, hay phương pháp với cộng đồng khoa học quốc tế.

\section{3. Định hướng tương lai}

\subsection{Các bài học trên thế giới}

So với thực trạng phát triển còn ở giai đoạn manh nha bước đầu tại Việt Nam thì thế giới đang chứng kiến những thay đổi chóng mặt đem lại ảnh hưởng rộng khắp. Hiệu quả đầu tư khoa học là chủ đề trọng tâm trong triển khai các dự án khoa học - giáo dục đối với mọi tổ chức chính sách, quản trị và tài trợ (Vuong, 2018). Có thể kể đến các bảng xếp hạng các cơ sở giáo dục như một ví dụ điển hình. Các bảng xếp hạng này tiến hành tính toán năng suất và mức độ ảnh hưởng của các thành tựu khoa học lên đời sống xã hội cũng như ngay trong chính lĩnh vực học thuật. Trong số đó nổi bật lên một vài xu hướng khoa học đáng chú ý đang liên tục thay đổi cộng đồng học thuật và đặc biệt là hệ thống tài trợ khoa học như dữ liệu mở, phản biện mở và minh bạch $100 \%$ (kể cả là sau khi xuất bản như hướng F1000Research, Wellcome Open Research (https://wellcomeopenresearch.org/ ) Bill và Melinda Gates Foundation (https://gatesopenresearch.org/ ) đang thực thi), đánh giá cộng đồng hay Plan S, v.v. Mức độ rộng và sâu trong kết nối toàn cầu dựa trên hạ tầng tốc độ Internet cùng các tài nguyên dựa trên và phục vụ chính hạ tầng này chính là là tiền đề của thời đại cách mạng công nghiệp 4.0. Trong bối cảnh đó, đối tượng chịu tác động trực tiếp và được thụ hưởng nhất là giới nghiên cứu hàn lâm, cụ thể là các nhà khoa học. Ảnh hưởng này đã được Holly Else nhắc đến khi phân tích về Plan $S$ trên Nature và dự báo về sự biến mất của các tạp chí "đóng" chỉ dành cho người đăng ký và trả phí (Else, 2018).

Không nằm ngoài xu thế kết nối, trên thực tế, công việc bình duyệt khoa học cũng đang dần trở nên công khai, hướng tới việc thành lập các CSDL tập trung các hồ sơ bình duyệt như của Publons. Khởi điểm là một startup tại một trường đại học ở New Zealand về CSDL bình duyệt, Publons được Clarivate Analystics sáp nhập và ngay lập tức kết nối vào CSDL ISI Web of Science cũng như ScholarOne Manuscripts ${ }^{\mathrm{TM}}$, hệ thống quản lý biên tập khoa học của Clarivate. Kết quả là sản lượng công việc của hàng triệu nghiên cứu viên toàn thế giới cũng như thực trạng tình hình công tác bình xét khoa học được thống kê và dữ liệu hoá trong các báo cáo và đánh giá. Điều này là không tưởng ở thời điểm cách đây chưa tới 10 năm. Đơn giản hơn là các kho dữ liệu mở trực tuyến và hệ 
thống Preprints Servers lưu giữ bản thảo hoàn toàn miễn phí đang tồn tại rất nhiều và không ngừng gia tăng nhu: Dryad, Dataverse, UK Data Archive, Figshare, OSF, Zenodo, arXiv, v.v. Mức độ minh bạch cao tới mức nếu tác giả muốn gỡ xuống một file sau khi đã được tải lên thì hành động xoá này vẫn lưu lại dấu vết. Tất cả những thay đổi này đều xoay quanh đội ngũ các nhà nghiên cứu.

Trong khi đó, người hàng xóm của Việt Nam là Trung Quốc đã nhận ra tầm quan trọng của việc thúc đẩy nghiên cứu khoa học đối với sự phát triển của đất nước trong thế kỉ 21 từ cách đây hơn 20 năm. Năm 1995, đề án 211 được phê duyệt nhằm cải tổ hơn 100 viện nghiên cứu và trường đại học để đáp ứng yêu cầu của thời đại mới. Đến năm 2015 , Trung Quốc ban hành kế hoạch "Song Nhất Lưu" (双一流) tập trung vào các trường đại học mạnh nhất với mục tiêu hướng tới chuẩn quốc tế. Cụ thể, Bộ Giáo dục Trung Quốc ban hành hai danh sách: một danh sách gồm các trường đại học mạnh nhất và một số trường khác với các khoa mạnh nhất; danh sách thứ hai liệt kê các ngành và lĩnh vực cần được tập trung phát triển bởi các đơn vị trong danh sách 1. Sự đúng đắn trong các quyết sách của chính phủ Trung Quốc đã được minh chứng qua xu hướng trỗi dậy của trường đại học Thanh Hoa với nhiều công trình thuộc khối ngành STEM có lượng trích dẫn thuộc top $10 \%$ thế giới trong khi đại học Bắc Kinh là cái nôi của các nhà tư tưởng. Hai trường đại học hàng đầu Trung Quốc này đã thành công phát triển mô hình đại học nghiên cứu chuẩn quốc tế.

Để có được kết quả này không thể không kể đến tiềm lực tài chính mạnh mẽ của nền kinh tế Trung Quốc. Điều đó được thể hiện qua các chính sách tài trợ hay quy định về thưởng có giá trị và mang tính tôn vinh cao. Cụ thể, mức thưởng cao nhất đối với một sản phẩm khoa học công bố trên Nature hay Science đối với các nhà khoa học Trung Quốc là hơn 3 tỷ VND. Bên cạnh đó, ngân sách dành cho phát triển khoa học 5 năm 2016-2020 của nước này lên đến 34 tỷ USD, chủ yếu đẩy mạnh nghiên cứu về các vấn đề cơ bản của cơ bản. Điều này thể hiện quyết tâm của chính phủ Trung Quốc trong việc xác định khoa học căn bản là nền tảng của phát triển bền vững trong kỉ nguyên số.

Bên cạnh các chính sách hỗ trợ về tài chính, thành tựu của Trung Quốc còn dựa trên những đầu tư dài hạn về đào tạo và thu hút nhân lực. Đại học Thanh Hoa là đơn vị đi đầu trong việc gửi các sinh viên xuất sắc ra nước ngoài bồi dưỡng. Hàng ngũ quản lý chủ nhiệm khoa của đại học Thanh Hoa cũng có những cá nhân tu nghiệp tại các trường đại học hàng đầu Hoa Kì như Columbia, Yale, Harvard, Stanford, Johns Hopkins hay Princeton. Chế độ đãi ngộ của các trường tại Trung Quốc cũng được xây dựng tương 
xứng để thu hút nhân tài với mức lương 6 chữ số và cơ chế biên chế và đánh giá năng lực tương tự mô hình của Hoa Kì. Thành tích và thăng tiến trong sự nghiệp của các giảng viên và nhà nghiên cứu sẽ được đánh giá dựa trên sản phẩm khoa học được công bố.

Bên cạnh việc hỗ trợ gia tăng sản lượng công bố khoa học, những thay đổi này cũng đặt ra thách thức nhằm hướng tới đỉnh cao trong học thuật. Đây là kết quả của mâu thuẫn tồn tại giữa yêu cầu về sản lượng với tiêu chí về chất lượng. Phát biểu suy nghĩ về vấn đề này, Yang Bin, Phó CT Đại học Thanh Hoa, một ngôi trường với thực lực đang trên đà phát triển cho rằng "Kết quả này tốt trong ngắn hạn, nhưng không tốt cho sự nghiệp gì đó lớn lao, những tư tưởng khoáng đạt. Quá nhiều người mang trong mình suy nghĩ của kẻ đi bắt chước. Họ không có đủ căn tính khởi nghiệp. Tôi nói với họ [các giáo sư]: Hãy dựng ra lĩnh vực mới. Đừng để tâm quá đến kiểu đánh giá, khen ngợi tầm thường từ đồng nghiệp. Hãy chấp nhận rủi ro cả sự nghiệp vì điều gì đó lớn lao." (The Economist, 2018).

Những thay đổi trên thế giới, nhất là ở các nước phát triển lâu đời phương Tây, còn có thể được xem là xa xôi. Nhưng điều đang thay đổi ngay trong giới tác giả và biên tập khoa học ở nước láng giềng Trung Quốc thì sẽ khiến cộng đồng KH Việt Nam phải suy ngẫm và trăn trở, và đổi mới với tinh thần cầu thị.

Ở một góc nhìn khác, tư duy và tinh thần khoa học không chỉ giới hạn ở giáo dục đại học mà còn có thể được khuyến khích và vun đắp từ những bậc học phổ thông. Ở các nền giáo dục tiên tiến trên thế giới, các hoạt động khám phá trải nghiệm khoa học từ lâu đã được tích hợp vào chương trình học nhằm chuẩn bị nền tảng tư duy và kĩ năng nghiên cứu cho thế hệ tương lai. Bởi vậy, ngay từ lứa tuổi phổ thông, học sinh đã có thể tham gia nghiên cứu khoa học và có những thành tựu cũng như đóng góp chân chính cho cộng đồng học thuật. Đặc biệt, nổi bật gần đây là một nghiên cứu mới được công bố về chủ đề các tác phẩm văn học được giảng dạy trong nhà trường có sự tham gia của 7 em học sinh từ lớp 5 đến lớp 7 tại một trường tiểu học ở Ba Lan Deszcz-Tryhubczak et al. (2019). Dưới sự dẫn dắt của hai tác giả chính, các em đều tham gia đóng góp tích cực trong quá trình định hình các bước nghiên cứu, khảo sát, phân tích kết quả và sản xuất bản thảo. Cụ thể, các nhà nghiên cứu nhỏ tuổi góp phần phân hoạch và tạo dựng câu hỏi cho bảng khảo sát dựa trên một danh sách các tác phẩm văn học chủ chốt trong chương trình học. Các em cũng tiến hành phỏng vấn bán cấu trúc với phụ huynh và các thành viên khác trong gia đình xoay quanh những kiến thức mà người được phỏng vấn có thể nhớ được từ chương trình học phổ thông. Toàn bộ quá trình không có sự can thiệp quá sâu từ hai 
tác giả dẫn dắt. Thành công của nhóm tác giả cho thấy một mô hình khả thi có thể được tham khảo rộng rãi trên thế giới về phương pháp dạy học khoa học lứa tuổi tiểu học.

\subsection{Hướng đi cho Việt Nam}

Tiêu chí quốc tế trong đại học

Những ví dụ và phân tích từ những phần trước của bài viết này đã cho thấy trong quá trình chuyển đổi các trường đại học và học viện sang định hướng nghiên cứu, việc áp dụng các chuẩn quốc tế đối với trình độ đào tạo và sản phẩm khoa học trong đánh giá, xét duyệt bổ nhiệm chức danh và vị trí quản lý trong ngành giáo dục là không thể tránh khỏi. Trên thực tế, các chính sách tại Việt Nam đã bước đầu áp dụng các quy định quốc tế trong tuyển dụng và bổ nhiệm các vị trí trong trường đại học. Đặc biệt có thể kể đến một số quy định mới ban hành gần đây về tiêu chuẩn về công bố quốc tế đối với ứng viên tiến sĩ, giảng viên hướng dẫn tiến sĩ, ứng viên chứng danh phó giáo sư và giáo sư.

Tại Việt Nam, vấn đề bình đẳng giới đã thu hút nhiều sự quan tâm trong thời gian gần đây, đặc biệt với sự phát triển của thông tin và liên lạc cũng như kinh tế xã hội giúp cho nữ giới có nhiều cơ hội khẳng định vai trò và tiềm năng tương quan so với nam giới. Mặc dù vậy, về cơ bản, xã hội Việt Nam vẫn tồn tại những quan niệm nhất định về "thiên tính" giới liên quan tới phân công lao động, dẫn đến những định kiến về nghề nghiệp phù hợp dành cho phụ nữ không cần quá nặng nhọc và nên mang tính kết nối, chăm sóc hơn như y tế hay giáo dục (UNESCO and KWDI, 2013). Theo thống kê từ Bộ Giáo dục và Đào tạo, trong năm học 2017-2018, cả nước có 36550 giảng viên nữ, chiếm 48.74\% tổng số giảng viên đại học cả nước. Tuy nhiên, trong vòng 10 năm từ 2008 - 2018, số lượng nhà khoa học nữ tham gia nghiên cứu và công bố trong lĩnh vực KHXHNV luôn ít hơn số tác giả nam (xem Hình 3).

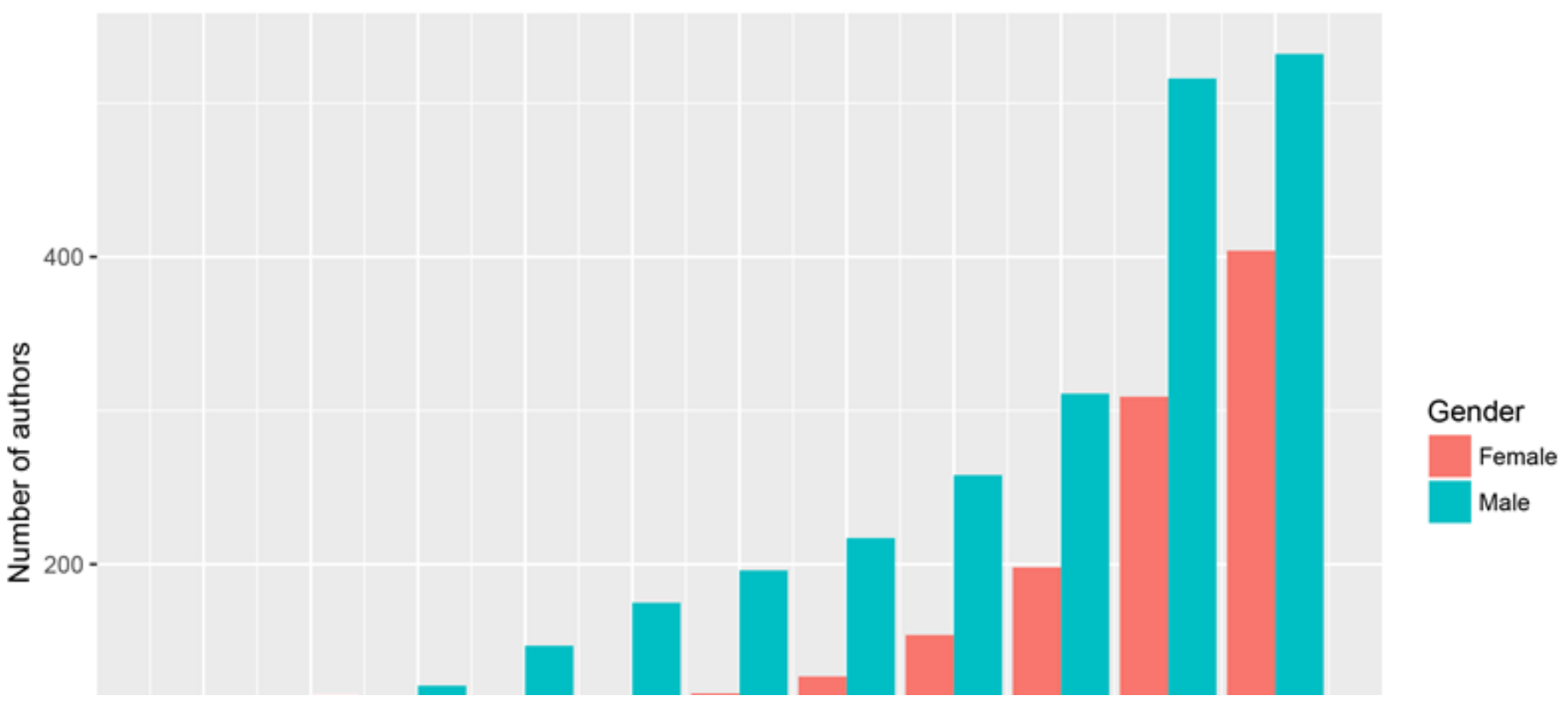




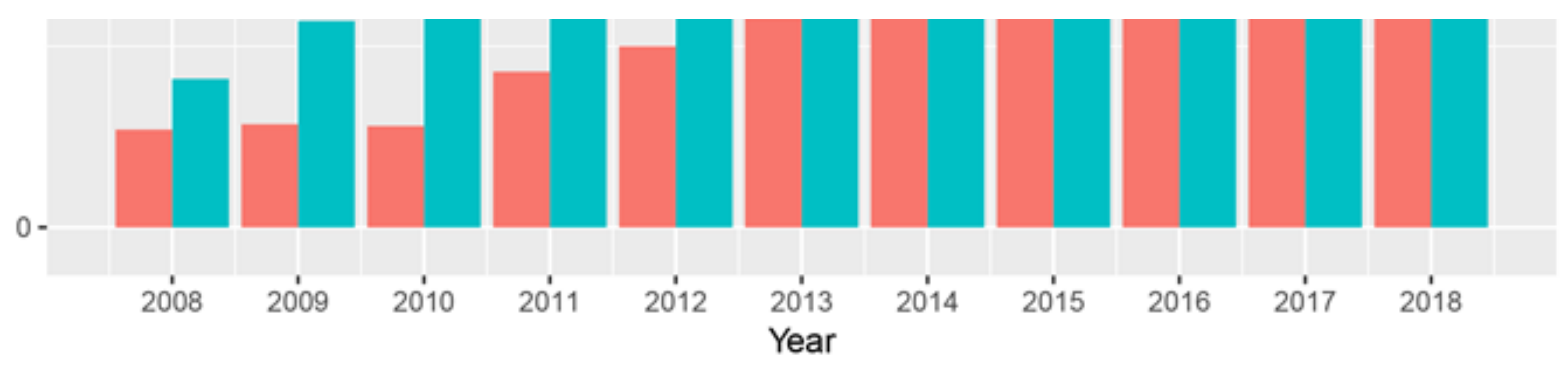

Hình 3. Tổng số tác giả có công bố quốc tế hàng năm theo nam/nữ trong giai đoạn 2008 - 2019 (tính đến ngày 05-05 theo CSDL SSHPA)

Đặc biệt, số lượng giảng viên nữ được phong tặng các chức danh giáo sư, phó giáo sư luôn rất thấp so với nam giới, chỉ chiếm $29.2 \%$ trong tất cả các lĩnh vực tính đến năm 2017 (HĐCDGS, 2019). Đây là một sự thiếu hụt rất lớn về tài nguyên con người đối với ngành nghiên cứu khoa học của đất nước vì phụ nữ hoàn toàn có khả năng lao động trí óc và đóng góp cho nền tri thức nhân loại tương đương với nam giới. Chỉ bằng việc tạo điều kiện hỗ trợ, khuyến khích để các giảng viên và nhà khoa học nữ có nhiều cơ hội tham gia nghiên cứu thì sản lượng khoa học cả nước sẽ có thể tăng đáng kể. Đặc biệt, các chính sách về minh bạch tiền lương và phúc lợi cũng như đảm bảo công bằng trong quy trình bình bầu và xét duyệt bổ nhiệm chức danh và vị trí quản lý đóng vai trò quan trọng trong việc khẳng định năng lực của phụ nữ, từ đó tạo động lực để thúc đẩy năng suất. Trên thực tế, trong suốt giai đoạn 2008 - 2018, số lượng các tác giả nữ mới tham gia nghiên cứu và công bố luôn tăng đều và đến năm 2018, con số này đã vượt qua các tác giả nam (Hình 4). Tỷ lệ nữ đạt chức danh giáo sư, phó giáo sư cũng tăng mạnh năm 2017, 1.16\% so với năm 2016 và trong một số lĩnh vực như Dược học và Giáo dục học, số lượng nữ giáo sư và phó giáo sư đã vượt hơn nam giới (HĐCDGS, 2019). Điều này càng chứng minh tiềm năng rất lớn của một nửa lực lượng nhân sự công tác khoa học của Việt Nam.

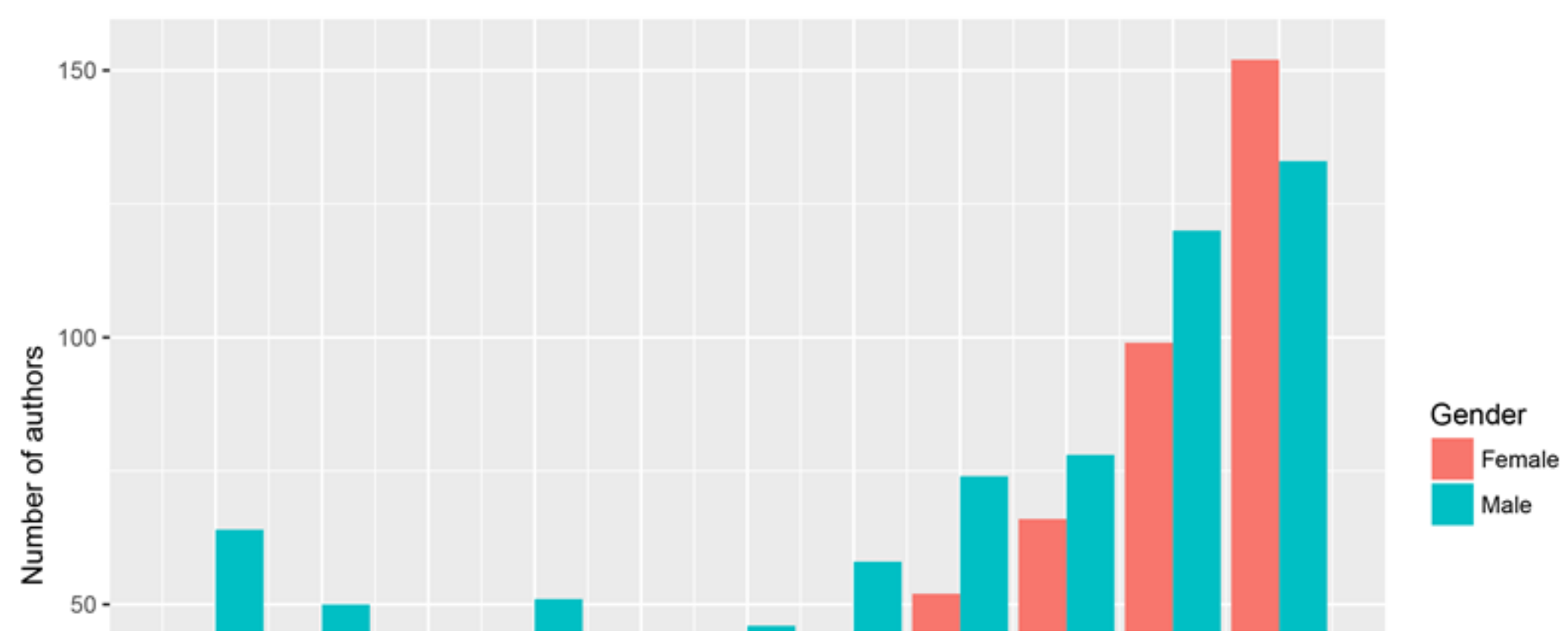




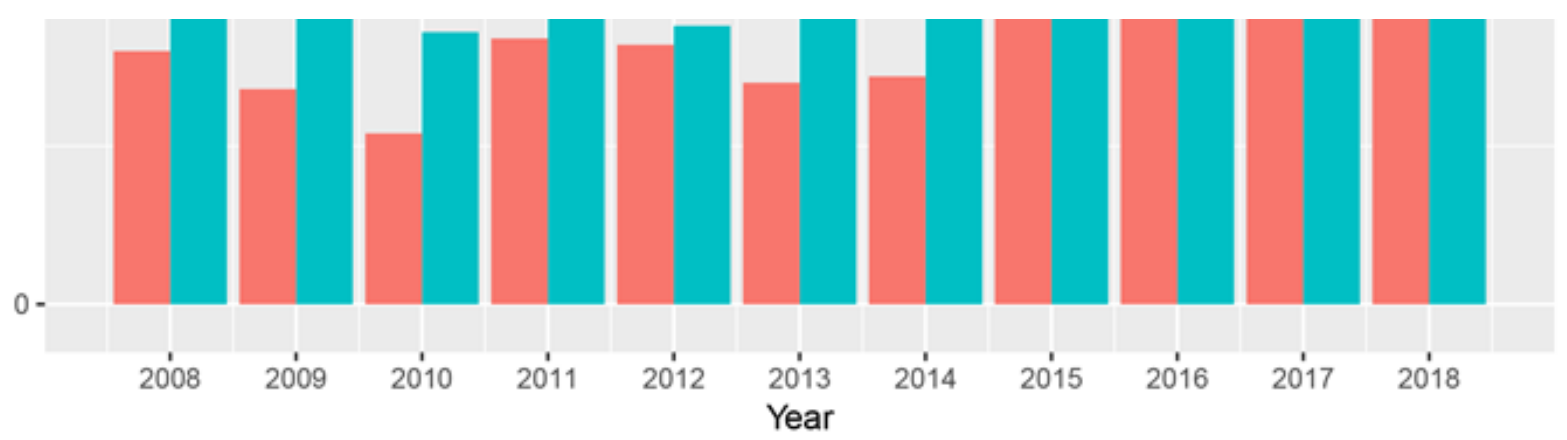

Hình 4. Số tác giả mới có công bố quốc tế hàng năm theo nam/nữ trong giai đoạn 2008 - 2019 (tính đến ngày 05-05 theo CSDL SSHPA)

Tư duy và tiếp cận khoa học từ bậc phổ thông

Những năm gần đây, STEM nổi lên như một giải pháp giáo dục cho những thách thức về chất lượng nguồn nhân lực trong thời đại 4.0 khi một số lượng lớn các ngành nghề bị thay thế bởi tự động hoá. Từ góc nhìn nâng cao năng lực nghiên cứu khoa học, giáo dục STEM với những đặc thù như tích hợp liên môn và xuyên môn, chú trọng tư duy hệ thống, tư duy phản biện, kĩ năng sáng tạo, v.v là nhân tố không thể thiếu trong chương trình giáo dục phổ thông nhằm nuôi dưỡng tri thức cho tương lai đất nước. Hoà chung với xu thế trên thế giới, giáo dục STEM đang nhận được rất nhiều sự quan tâm và bước đầu đã được triển khai tại Việt Nam dưới hình thức các câu lạc bộ ngoài giờ'.

Tuy nhiên, việc đưa giáo dục STEM vào áp dụng trên thực tế Việt Nam đang gặp nhiều khó khăn trở ngại. Cụ thể, tác giả Đỗ Thanh Hải trong cuốn sách về Giáo dục STEM đã đưa ra những ngộ nhận thường gặp về giáo dục STEM trong đó nổi bật là cách nghĩ STEM là chỉ học các môn khoa học tự nhiên, lắp ráp kĩ thuật nên chỉ dành cho học sinh nam và đồng thời phủ nhận vai trò của giáo dục xã hội và nhân văn. Sau khi tổng hợp các nghiên cứu mới nhất trên thế giới về giáo dục STEM, tác gỉa đã chứng minh giáo dục STEM thực chất lại giúp hỗ trợ cho việc học các môn khoa học xã hội và nhân văn của học sinh. Điều này là bởi các kĩ năng được rèn luyện trong các lĩnh vực STEM như tư duy trừu tượng, phản biện, khả năng sáng tạo cũng là nền tảng để học tốt các môn xã hội và nhân văn. Thêm vào đó, trong quá trình đọc sách, quan sát và tìm tòi cuộc sống thực tế để tạo nguồn ý tưởng và sáng kiến về khoa học công nghệ, học sinh sẽ phát triển cảm xúc ở mức độ cao hơn, cũng như hình thành các kĩ năng xã hội và kiến thức sâu rộng về lĩnh vực nhân văn.

Cùng chung vấn đề về tiếp cận giáo dục STEM cho trẻ em nữ, nhiều nghiên cứu trong và ngoài nước đã chỉ ra tình trạng bất bình đẳng về giới trong giáo dục STEM tại Việt Nam. 
Theo báo cáo khảo sát của UNESCO về các yếu tố ảnh hưởng tới tiếp cận, tiến độ và thành tựu của trẻ em nữ và phụ nữ, các yếu tố liên quan đến trường học bao gồm giáo viên, giáo trình và học liệu, các cơ hội trải nghiệm và cơ chế kiểm tra khảo thí. Cụ thể, các kết quả nghiên cứu cho thấy học sinh nữ có xu hướng tham gia tích cực vào giờ học STEM và tương tác tốt hơn khi giáo viên là nữ (Rabenberg, 2013). Các em cũng được truyền cảm hứng nhiều hơn và do đó tự tin cũng như chủ động hơn đối với các lĩnh vực STEM và lựa chọn STEM để theo đuổi ở bậc học cao hơn (Carrell, Page, \& West, 2010; Stearns et al., 2016). Kết luận này nhấn mạnh sự cần thiết trong việc nâng cao nguồn cung về giáo viên STEM, cả về số lượng và chất lượng, đặc biệt là giáo viên nữ. Đây là thách thức không nhỏ khi đào tạo nghề ở nước ta vẫn còn nặng định kiến về giới và có thể chưa thực sự hỗ trợ tốt cho học viên nữ trong việc tìm kiếm và theo đuổi các cơ hội nghề nghiệp đa dạng (Kabeer, Van anh, and Manh, 2005). Do vậy, chúng ta cần có sự phối hợp chặt chẽ hơn giữa các cơ sở đào tạo và doanh nghiệp cũng như các đơn vị sự nghiệp để hỗ trợ nữ lao động lựa chọn các lĩnh vực nghề nghiệp đa dạng, trong đó có khối ngành STEM trong sư phạm.

Về khía cạnh giáo trình và học liệu, nghiên cứu của Viện Khoa học Giáo dục Việt Nam đã cho thấy số tác giả nữ tham gia viết sách giáo khoa cho chương trình phổ thông hiện hành toàn quốc vẫn ít hơn so với tác giả nam, đặc biệt là ở cấp trung học. Riêng đối với sách giáo khoa các lĩnh vực STEM, hình minh hoạ và ngành nghề của các nhân vật phần lớn là nam giới. Việc thiếu hụt các hình ảnh đại diện và ví dụ về nữ giới trong giáo trình và tài liệu học tập sẽ khiến học sinh nữ gặp khó khăn trong phát triển đam mê hứng thú với các môn học STEM và cũng thiếu quyết tâm và tự tin hơn khi tiếp tục học lên cao trong lĩnh vực này (Huyer \& Westholm, 2007). Những tồn tại này cho thấy tầm quan trọng của việc khuyến khích tác giả nữ tham gia và quá trình biên soạn và chỉnh sửa, góp ý sách giáo khoa và giáo trình cũng như đẩy mạnh công tác bồi dưỡng nâng cao nhận thức của giáo viên về STEM và nhạy cảm giới. Việc thể hiện vai trò giới tính trong nội dung giáo trình và học liệu phải được thực hiện cẩn thận, tránh tình trạng quá tập trung vào ý thích và góc nhìn của nữ giới vì sẽ càng làm gia tăng định kiến giới vốn đã tồn tại sẵn (Fousyia and Musthafa, 2016). Đồng thời, tuy việc thể hiện hình ảnh sinh viên nữ theo học các ngành STEM ở bậc cao là cần thiết để truyền cảm hứng cho học sinh, thiết kế những nội dung này cần thận trọng để tránh tạo ấn tượng các môn STEM khó và quá sức với học sinh (Rosenzweig \& Wigfield, 2016).

Báo cáo của UNESCO cũng chỉ ra ảnh hưởng của công tác khảo thí lên kết quả học tập lĩnh vực STEM của học sinh theo giới tính. Trong khi trẻ em nam thường có khả năng làm 
tốt hơn đối với những bài kiểm tra trắc nghiệm và chuẩn hoá có thể do xu hướng mạo hiểm cao hơn thì trẻ nữ có ưu thế với các dạng bài dự án và viết luận, có khả năng vì thiên hướng ngôn ngữ và kết nối hợp tác (Eurydice, 2010). Đặc biệt, sự căng thẳng lo lắng của giáo viên có khả năng ảnh hưởng tới học sinh nữ, khiến kết quả kiểm tra của nhóm này thấp hơn trong khi học sinh nam hầu như không chịu tác động tương tự (Beilock, Gunderson, Ramirez, \& Levine, 2010).

Tóm lại, kết quả của các cuộc khảo sát đều cho thấy cốt lõi của các giải pháp nhằm nâng cao giáo dục STEM tại Việt Nam tập trung vào cải thiện nguồn nhân lực. Trình độ, nhận thức, các yếu tố về tâm lý và khả năng sư phạm của giáo viên đều có thể có tác động đến chất lượng giáo dục STEM và kết quả học tập của học sinh. Các chương trình, dự án tăng cường nhận thức và nâng cao năng lực chuyên môn của giáo viên trong giảng dạy và tiếp cận STEM có thể mang lại hiệu quả trong thời gian ngắn hạn. Để triệt để khắc phục những tồn tại hiện nay, chúng ta cần tập trung đầu tư vào các hoạt động đào tạo dài hạn nguồn nhân lực, đặc biệt là đội ngũ sinh viên sư phạm các lĩnh vực STEM. Với điều kiện hạn chế về cơ sở vật chất cũng như các nguồn lực tài chính khác của nước ta, việc giáo viên được đào tạo tư duy khoa học với các kĩ năng cần thiết phục vụ việc tự nghiên cứu và mở mang, cập nhật kiến thức là rất quan trọng để có thể phát huy tính sáng tạo cũng như năng lực thích nghi, cải thiện và vượt lên các điều kiện hạn hẹp về bối cảnh. Bên cạnh đó, các chính sách, quy định cải thiện vấn đề bình đẳng trong tiếp cận giáo dục STEM ở phổ thông và theo đuổi ngành nghề STEM ở bậc đại học cũng rất cần thiết để tránh lãng phí tiềm năng nhân lực của đất nước.

Dữ liệu, phương pháp, và truyền thông khoa học

Để đón đầu được các xu hướng của thế giới, Việt Nam nên bắt đầu từ đâu? Đây là câu hỏi không hề dễ dàng, xét trong bối cảnh khoa học thế giới cũng đang trải qua nhiều biến đổi. Tuy nhiên, có ba yếu tố có thể trở thành nền tảng quan trọng cần được thực hiện: cơ sở dữ liệu, phương pháp tiên tiến, và truyền thông khoa học.

Trí thông minh nhân tạo có thể phát triển trong thời đại hiện nay nhờ rất nhiều vào lượng dữ liệu khổng lồ mà con người sản xuất ra hàng ngày. Dữ liệu vì thế trở thành một tài sản quan trọng đối với mỗi quốc gia. Xây dựng các cơ sở dữ liệu lưu trữ dữ liệu phục vụ cho khoa học, cho y tế, cho giáo dục sẽ tạo nên một nguồn tài nguyên 4.0 dồi dào. Nguồn dữ liệu đó có thể hỗ trợ cải thiện dịch vụ y tế, phục vụ giảng dạy. Đối với các nhà nghiên cứu, các sản phẩm công bố sử dụng dữ liệu đó sẽ giúp hiểu thêm về xu hướng và các 
vấn đề xã hội. Cuối cùng, lưu trữ dữ liệu cũng là một cách bảo tồn văn minh những câu chuyện cổ, những căn nhà cổ trước sự bào mòn của thời gian.

Để khai thác được lượng dữ liệu đó, phương pháp tiếp cận dữ liệu hiện đại như phân tích Bayesian có thể sẽ mang lại điểm tựa vững chắc cho các nhà khoa học (Vuong and La, 2019). Một số nghiên cứu gần đây sử dụng phân tích Bayesian đã khám phá ra những hiện tượng văn hóa độc đáo dựa trên truyện cổ tích (Vuong et al., 2018) hay nhà cổ Hà Nội (Vuong et al., 2019). Hiện nay, trong khi phương pháp thống kê cổ điển đang gặp phải sự đánh giá khắt khe trên thế giới thì việc sử dụng, nắm vững và làm chủ phương pháp Bayesian sẽ giúp khoa học Việt Nam, đặc biệt là KHXHNV, vượt qua khỏi giới hạn để hướng đến các giá trị tri thức trường tồn.

Cuối cùng, cấu trúc phức tạp của mỗi nghiên cứu khoa học cần được truyền tải cô đọng tới độc giả đại chúng. Vì vậy, truyền thông khoa học là một yếu tố quan trọng để giúp xã hội hiểu hơn về công việc nghiên cứu, và tại sao mỗi bước tiến của nó lại quan trọng với xã hội. Những nỗ lực truyền thông khoa học (SciComm) trên thế giới đang được thúc đẩy mạnh mẽ, thậm chí đã và đang trở thành một ngành nghề thu hút một lượng lớn các nhà nghiên cứu, hoặc những người đã từng trải qua những thời kỳ nghiên cứu khoa học chuyên nghiệp. Thực tế này khiến cho SciComm ngày càng có hình dáng của một công việc chuyên nghiệp, khiến cho chất lượng thông tin qua các phương tiện đại chúng được cải thiện nhanh chóng. SciComm cũng góp phần giúp định hướng thế hệ trẻ của thời đại 4.0, thậm chí từ khi còn ngồi trên ghế nhà trường phổ thông trở nên yêu mến, hiểu biết về công việc khoa học và có định hướng ngành nghề sớm hơn các thế hệ trước./.

Vương Quân Hoàng

Trường Đại học Phenikaa, Hà Nội

Nguồn: Trang thông tin điện tử Hội đồng lý luận Trung ương

\section{Like 2} $\boldsymbol{y}$ Tweet

Tags: giáo dục . Nghiên cứu . vai trò . Việt Nam . thời đại 4.0

\section{Các tin khác}




\section{GỬI TIN NHẮN}

Nội dung

\section{Gửi}

\section{THỐNG KÊ TRUY CẬP}

Đang truy cập: 209

(.) Hôm nay: 11670

粒 Tháng hiện tại: 485376

(Tổng lượt truy cập: 14060354

Giấy phép xuất bản thông tin số 125 /GP-BC do Bộ Thông tin và truyền thông cấp ngày 02/4/2008.

Bản quyền (c) 2008 - 2019 thuộc Học viện Cảnh sát nhân dân.

Địa chỉ: Phường Cổ Nhuế 2, quận Bắc Từ Liêm, thành phố Hà Nội.

Điện thoại: 84-024-38362811 - 069-2346002 - Fax: 84-024-38362801 - Email: info@hvcsnd.edu.vn.

Chịu trách nhiệm nội dung: Thiếu tướng, GS.TS Nguyễn Đắc Hoan - Phó Giám đốc Học viện, Tổng biên tập.

Thiết kế bởi Acomm

http://hvcsnd.edu.vn/nghien-cuu-trao-doi/dai-hoc-40/ve-vai-tro-cua-nghien-cuu-trong-giao-duc-vietnam-thoi-dai-4-0-5498 